\title{
The weakness and strengths of sanitary inspections in improving food safety and hygiene in commercial restaurants in Rwanda
}

\author{
Noël Korukire ${ }^{1 *}$, Liliane Birasa ${ }^{2}$, David Basheija ${ }^{3}$, Jean de Dieu Habimana ${ }^{1}$, M. Claire Ineza ${ }^{4}$ \\ 1. School of public health, College of Medicine and Health Sciences, University of Rwanda \\ 2. American refugees committee, Rwanda program \\ 3. Centre of Language Enhancement, College of Medicine and Health Sciences, University of Rwanda \\ 4. School of dentistry, College of Medicine and Health Sciences, University of Rwanda \\ *corresponding author: Noël Korukire (koranoe1980@gmail.com)
}

\begin{abstract}
Background: Food business in restaurants has undergone a significant development and it is attributed to the increase of urban population. This sector has big economic benefits. On the other hand, a large number of people may contract illnesses and others may die as result of eating contaminated food in these food premises. Therefore, sanitary inspections are conducted with the aim to stop food mishandling and to ensure that hygienic measures are taken in commercial restaurants. Objective: The aim of this paper was to highlight some weakness and strengths of sanitary inspections in improving food safety and hygiene in commercial restaurants in Rwanda. Methods: The authors reviewed literature to support their views. Results: Authors reveal that these inspections have some weaknesses such as unclear guidelines or unclear standards, and in some cases these inspections have accused for penalties instead of improving food safety and hygiene in restaurants and other public places. Conclusion: The authors conclude that though there are some strengths but these sanitary inspections might have a little contribution in the improvement of food safety and hygiene in commercial restaurants and other public places. The authors show their outlook for improvement, such as setting up clear standards as well as establishment of policies, laws and guidelines pertaining to the operation of commercial restaurants.
\end{abstract}

Keywords: Commercial restaurants, sanitary inspection, food safety

\section{Background}

The food business in restaurants has undergone a significant development due to the population increase in urban and peri urban areas.[1,2] However, restaurants are likely to be a potential source of hazard to public health due to food borne illness outbreaks which might be linked to unsuitable environments for food operations, poor sanitary practices in food service establishment, poor personal hygiene and other environmental factors as well as improper holding temperatures.[3] A number of studies have documented that poor sanitary practices in restaurants favor the growth of bacterial pathogens that contribute to food borne diseases. [6,2,5] A study conducted in United states showed that 52.1\% of food borne diseases were attributed to commercial restaurants.[6] In Africa also many cases of deaths due to food borne illness were declared and these cases were attributed to poor hygiene conditions in restaurants. $[4,7,8]$

Sanitary inspections in restaurants are important for the prevention of food borne diseases to the consumers by ensuring good hygiene conditions.[1] Literature show that sanitary inspections is an important tool to be used by regulatory agency to detect hazardous procedures, enhance good practices, and recommend appropriate action.[3] Globally restaurants inspections are regularly conducted to prevent food borne disease and maintain reasonable standards. [1,9] In United States in preventing food borne diseases, restaurants are regularly inspected by competent bodies such as local, county or state health department personnel[1] and these inspections have caused a significant reduction of food borne diseases that cause hospitalization[10] 
In Rwanda, the Ministry of Health in collaboration with other ministries, National Police, and local administrations such as districts and City of Kigali conduct sanitary inspections to ensure that the food safety measures are taken and hygiene in public places including hotels, motels, restaurants etc is maintained. The author of this personal view paper was aiming at highlighting the strengths and weaknesses of sanitary inspections in the context of improving the food safety and hygiene in commercial restaurants in Rwanda. The author reviewed different literatures in relation to sanitary inspections and food hygiene in commercial restaurants to supports their views. Those strengths and weaknesses are discussed in the sections below.

\section{Availability of inspection teams}

Countrywide, there are different teams which have the responsibility of conducting sanitary inspections to improve the food safety and hygiene status of commercial restaurants and other public places such as bars, schools, and so on. In the City of Kigali the team is composed of different professionals coming from different institutions. They have skills and knowledge in the domain of health inspections and other related domains. The team conducts an educative sanitary inspection to improve hygiene status in public places and food safety. The team conducts inspections regularly on quarterly basis, and it follows the inspection guidelines and standards established by the City of Kigali and they make a report of inspections as well as make a follow up.[11] Although inspections teams are available in the whole country, as well as existence of guidelines and standards at the level of some districts as well as the city of Kigali,[11] these inspections have some weaknesses which are highlighted in this paper.

\section{National guidelines and laws pertaining to restaurants operations}

Sanitary inspections normally contribute to the improvement of the of food safety and hygiene status of restaurants by providing operating permit or licenses for those who want to start food businesses. This is because consumers should take safe food which keeps them healthy and strong.[4] Therefore, pre-operational inspection and all other types of sanitary inspections for improving hygiene such as routine inspections, complaint inspections and follow-up inspections as well should be conducted with the purpose of making sure that these establishments fulfill all the requirements.[3]
Currently routine and follow up inspections are only being done, while the pre operation inspection is very important before starting the commercial restaurant. Therefore, there are should be laws and guidelines to be enforced. Although, in some districts these guidelines exist for instance in all district of the City of Kigali; however, there is no national guidelines governing the operations of commercial restaurants. As results a high number restaurants in Rwanda particularly in small towns and remote areas are operating without these permits or licenses, yet studies have documented a statistical association between the possession of license, and the sanitary conditions of a restaurant.[5]

Operating without permits or licenses is also linked to lack guidelines or lack of enforcement of laws that regulate the operation of these food businesses. Therefore, this situation leads restaurants to operate in poor hygiene conditions which will likely lead to food contamination in those public eating places, and as result, may cause significant public health problems.[12]

\section{Standards}

Food and hygiene standards are important for food safety and good health status. One of the aim of those standards is to assure the confidence of consumers in the food systems.[13] Lack of hygiene standards or unclear standards to comply with in commercial restaurants is a challenge to those who operate the food business, and it is also a challenge to those who conduct sanitary inspections. Even where those standards are available, they are not clear or detailed. For instance when standard require that a public eating place must have sufficient ventilation or sufficient lighting, e.g.: Article 21: requirements for a building serving as restaurant (a) of instruction of the city of Kigali, require restaurant to have a good ventilation,[11] it is not easy for the inspection team to measure or to confirm that a restaurants meets these requirements or not. As a result a large number of restaurants in different corners of the country operate without complying with standards as it is supposed to be.[5]

\section{Sanitary inspection due to events}

Currently a number of sanitary inspections are being conducted either because there are special events such as special guests or meetings which are expected to take place in a certain area, particularly in urban and peri urban areas, while routine educative inspections 
should be conducted regularly nationwide for the purpose of improving hygiene status in restaurants and making the owners aware and familiar with their obligation of complying with the food and hygiene standards. Thus, regular or routine inspections should be conducted to provide sufficient information on food hygiene practices, and to support legal action in case of violation of some food laws and guidelines.[14]

\section{Conclusion}

The authors of this paper aimed at highlighting some strengths and weaknesses of sanitary inspections for the improvement of food safety and hygiene in commercial restaurants in Rwanda and to highlight the authors' outlook. The main strength highlighted in this paper is the availability of sanitary inspections countrywide and skilled people who performed those tasks. However, there are significant weaknesses of these sanitary inspections. Furthermore, there is no doubt that if the concerned institutions such as Ministry of health, Rwanda Standard Board and districts authorities establish measures such as setting up clear standards for commercial restaurants operations, establishing policies, laws and guidelines pertaining to the operation of commercial restaurants, clearly defining licensing criteria as well as organizing regular inspections, the improvement of hygiene and food safety in restaurants will be achieved. This paper then recommends further research on the role and progress of sanitary inspections.

\section{Acknowledgement}

We thank Dr Theoneste Ntakirutimana and Dr Maryse Umugwaneza for stimulating ideas.

\section{Conflict of interest}

All authors declare no competing interest

\section{Contributors}

N.K wrote the first draft. Other authors provided critical input and searching literature to respond to author's comments.

\section{Reference list}

1. Jones TF, Pavlin BI, Lafleur BJ, Ingram LA, Schaffner W. Restaurant Inspection Scores and Foodborne Disease. 2004;10(4).

2. Rwanda Standards Board. Food Safety in Hotels and Restaurants-An Important Aspect of the Hospitality Sector Development. 2017.
3. US.Public Health Services. Food Code. Vol. 0001, Drugs. 2013. 237-304 p.

4. Muinde R. Hygiene Practices in Urban Restaurants : Investigating Possibilities of Introducing HACCP Systems in Thika Town A Thesis Submitted to the School of Hospitality and Tourism Management in Partial Fulfilment of the Requirements for the Degree of Master of Sc. 2010;1-109.

5. Mulugeta K. The Sanitary Conditions Of Food Service Establishments And Food Safety Knowledge And Practices Of Food Handlers In Bahir Dar Town. Ethiop J Heal Sci. 2012;22(1).

6. Kwon J, Roberts KR, Sauer K, Cole KB, Shanklin CW. Food Safety Risks in Restaurants and School Foodservice Establishments: Health Inspection Reports. 2012;25-35.

7. MoH. DISEASE HIGHLIGTHS : Every week, a disease is highlighted in the weekly Epidemiological bulletin to sensitize and familiarize readers with the various diseases under surveillance. This week, Diarrhea in Children aged under 5 years is featured Definitio. 2013;(January).

8. RBC/ESR. Epidemic Surveillance And Response Weekly Report, W19 May2016. 2016;1-8.

9. Cruz MA, Katz DJ, Suarez JA. An Assessment of the Ability of Routine Restaurant Inspections to Predict Food-Borne Outbreaks in Miami - Dade. 2000;3724:2000-2.

10. Paul. Impact of Restaurant Hygiene Grade Cards on Foodborne-Disease Hospitalizations in Los Angeles County. Jouranl Environ Heal. 2005;67(5).

11. CoK. Instructions of the City of Kigali Council relating to hygiene in the City of Kigali. 2016.

12. WHO. WHO global strategy for food safety. 2002.

13. Vieira LM. The Role of Food Standards in International Trade: Assessing the Brazilian Beef Chain. Brazilian Adm Rev. 2006;3(1, Art. 2):17-30.

14. Food \&Drug Administration. Investigations operations manual 2016 chapter 5 - Establishment Inspections. 2016;218-340. 